\title{
Implications of Contributions to Equity in Access of Health Care: A Case of Community Based Health Insurance Schemes in Kenya
}

\author{
Jane W. Gitahi ${ }^{1} \&$ Amos Gitau Njuguna ${ }^{2}$ \\ ${ }^{1}$ Doctorate canditate at United States International, Africa \\ ${ }^{2}$ Professor of Finance and Accounting, United states International Universaity, Africa \\ Correspondence: Gitahi W. Jane, Doctorate canditate at United States International, Africa. Tel: 254-726-495-058. \\ E-mail: jane6277@gmail.com
}

\author{
Received: September 4, 2017 Accepted: October 9, 2017 Online Published: January 8, 2018 \\ doi:10.5539/gjhs.v10n2p90 \\ URL: https://doi.org/10.5539/gjhs.v10n2p90
}

\begin{abstract}
The realization of equity goals requires commitment and combination of contributions from all stakeholders in the healthcare sector under the stewardship of the government. The purpose of this study was to examine the mix of contributions in Community Based Health Insurance Schemes (CBHIs) and equity in healthcare in Kenya. The sample was composed of 318 members of management teams drawn from 82 CBHIs. Descriptive statistics, factor analysis, path analysis and multivariate regression analysis in structural modeling equation (SEM) were conducted to determine the mix of contributions in CBHIs and its bearing on equity in healthcare in CBHIs in Kenya. The study concludes that current mix of contributions is not adequate enough to guarantee equity in access of health care for the poor and vulnerable groups. For realization of equity in access of health care governments and sectoral partners should define the place of CBHIs within the national health policy to guide establishment of an optimal combination of contributions in CBHIs for increased access to care and financial risk protection for precluded groups.
\end{abstract}

Keywords: mix of contributions, universal healthcare, equity, access of health care

\section{Introduction}

The subject of disparities and inequities in healthcare is now recognized as a global problem. Huge differences in health care access and high levels of financial risks associated with healthcare payments have been documented mostly in low and middle income countries (LMICs). Globally an estimated 400 million people lack access to essential health services, $17 \%$ of the people are impoverished or pushed deeper into poverty by healthcare costs (Starfield, 2011; WHO, 2015a; Asante, Price, Hayen, Jan, \& Wiseman, 2016) whilst almost a third of households in Africa and South East Asia regions (SEAR) are forced borrow money or sell assets to meet healthcare costs (Kruk, Godmann \& Galea, 2009). Enormous discrepancies in healthcare expenditure and as a consequence access to healthcare are evident among countries with LIMCs relying heavily on out of pocket (OOP) expenditure to finance healthcare. In 2013, households in LIMCs contributed $42.3 \%$ and $40.6 \%$ respectively of Total Health Expenditure (THE) compared to $21.2 \%$ in high income countries (WHO, 2016). Additionally, while poorer countries in African and SEAR of WHO account for over half of global burden of disease and 39\% of world's population they spent only 3\% of world health resources in 2012 (WHO, 2015b). Similarly, the WHO African region and SEAR are deprived of access to quality healthcare due to large deficits of skilled health workers $(4.2$ million and 6.9 million respectively). Within countries, the disparities in access are driven by differences in socioeconomic status with Sub-Saharan Africa and SEAR having the highest child mortality rates (WHO, 2016). The ensuing disparities in access to quality healthcare and financial protection places equity at the heart of current policy debates of Universal Health Coverage (UHC) and in the post 2015 Sustainable Development Goals (SDGs) agenda (WHO, 2015b). UHC was founded on the principle of access to healthcare for all with financial risk protection while SDGs are founded on the theme of inclusiveness.

Like many African countries, Kenya faces immense hurdles in finding adequate fiscal space for health necessary for UHC. Kenya is composed of a large informal sector and a comparatively small and stagnant formal sector (Kenya National Bureau of Statistics (KNBS), 2016). Community financing have been used all over world as a strategy for mobilizing resources to finance and deliver healthcare for the informal sector and the poor. Germany, Japan, China, Korea, Taiwan, Thailand and Indonesia and more recently Ghana and Rwanda has increased access 
to healthcare for the informal sector by enlisting the informal sector through small groups which eventually merged to larger schemes (Criel \& Van Dormael, 1999; Poletti, Balabanova, Ghazaryan, Kamal-Yanni, Kocharyan, Arakelyan \& Hakobyan, 2007; Fernandes et al., 2009; WHO, 2010; Durairaj, D'Almeida, \& Kirigia, 2010; Schieber, Cashin, Saleh \& Lavado, 2012). In Kenya CBHI schemes have evolved over time to take care of healthcare financing requirements of the low income households who have been left out of mainstream prepaid schemes (MoH, 2014).

\section{Literature Review}

\subsection{Health Financing in Kenya}

At independence Kenya's health system was predominantly tax- funded. As part of broader structural reforms the government liberalized its economy in the late 1980s. As a result, a user fee was introduced in the health facilities to cover part of services costs in government facilities. As a consequence there was challenge of affordability and decline in utilization of healthcare services especially among the poorest population (Chuma and Okungu, 2011). The user fee was modified following the introduction of free health services in dispensaries and health centers in 2004 (Carrin et al, 2007) and free maternity services in all public hospitals in 2013. In 2010, the Health Sector Services Fund (HSSF) was established as a systematic way of channeling pooled government and donor funds to level 2 and 3 facilities with an aim of cautioning them against decline in revenue associated with abolishment of user fees (Chuma and Okungu, 2011). Today Kenya operates a pluralistic health financing system with major contributors being government, households and donors.

\subsection{Health Insurance Coverage in Kenya}

Risk pooling mechanisms are poor with only $4 \%$ of all health funds are pooled through insurance (Chuma \& Okungu, 2011). The estimated health insurance coverage in 2014 was about $17.1 \%$ ( $44 \%$ of the population). Out of this coverage, the National Insurance Hospital Fund (NHIF) covered $88.4 \%$, while private insurance, Community Based Health Insurance Schemes (CBHI) and others forms of insurance covered 9.4\%, 1.3 and 1.0\% respectively. On the basis on wealth status, only $2.9 \%$ of the poorest quintile is covered (MOH, 2014).

\subsection{Mix of Contributions}

Like other countries that have espoused UHC, Kenya faces continuous challenges of trading off and balancing competing healthcare access demands as it moves along stages towards its realization and sustenance (Carrin et al., 2007). Recent analysis of health expenditure and financing flows in the health sector in 2012/13 National Health Accounts (NHA) shows that the private sector is major financier contributing $40 \%$ of THE, while government and donors contributed 34\% and 26\% of THE respectively (MoH, 2015). Estimates based on Ministry of Health (2014) indicate that OOP spending on outpatient and inpatient accounted for $78 \%$ (48.4 billion) and 22\% (13.7 billion) of total household health expenditure respectively (MOH, 2014).

Faced by increasing demand for healthcare services and limited fiscal space for health, Kenya began by targeting the formal sector through the national insurer, NHIF. This strategy has resulted into a two tier system making the conditions worse for the uncovered. The formal sector enjoys financial protection against health cost while majority in the informal sectors are not covered. Chuma \& Maina (2012) found that each year Kenyan households spend one tenth of their household budget on health expenses with the burden of OOP being highest among the poor. As a consequence the incidence of catastrophic health expenditure is high with approximately 1.48 million Kenyans being driven below the national poverty line each year.

It is against this backdrop of poor government spending in health and poor governance in the healthcare system that CBHIs have emerged. Some of the distinguishing characteristic of CBHIs is the enlisting community's participation that allows community's involvement in setting the premium employment of traditional self-help and social mobilization strategies that have been embraced by the poor in low income (Tabor, 2005; Schieber et al., 2012). They can therefore be employed innovatively in identifying pockets of exclusion in healthcare access for the poorest and socially excluded groups. The study examined the mix of contributions in CBHIs and how it impacts on equity in access of healthcare in CBHIs in Kenya.

\section{Methodology}

\subsection{Population and Sampling Design}

The population of the study was composed of 115 CBHIs registered in Kenya under the umbrella association of Kenya Community Based Health Financing Association (KCBHFA) in 2015 and had been in operation for a period of between 1-15 years. Thirty three CBHIs were omitted from the study due to lack of coherent data and intermittent periods of activity. The ensuing situation reduced the population of interest to 82 CBHIs. To make 
inference about the CBHIs, responses were sought from four members of each CBHIs management team translating to 328 respondents. A sample of 318 was drawn using Yamane (1967) formula. Data was collected between $23^{\text {rd }}$ March, 2016 and $14^{\text {th }}$ April, 2016. In total, 224 complete and usable questionnaires were received from the respondents, representing $70 \%$.

\subsection{Questionnaire and Secondary Data Sheet}

In order to obtain necessary information of the mix of contributions and equity in healthcare in CBHIs in Kenya a questionnaire divided in two sections was used. The first section sought information on independent variable (mix of contributions) determined by timeliness and adequacy contributions to CBHIs while the second section contained information on equity in healthcare (dependent variable) which was determined by access to care, quality of care, equity in contributions and sustainability. Responses were sought in a five point likert-type scale ranging from 1) Strongly disagree (2) disagree (3) Neutral (4) Agree (5) Strongly Agree. In addition a secondary data sheet was used to collect longitudinal data on total premiums collected (from households, government and donors), healthcare costs reimbursements and administration cost from each CBHIs from 2010-2015.

\subsection{Validity and Reliability of the Questionnaire}

The content validity of the questionnaire was guaranteed by determining of the degree to which data collected using a particular instrument represents a specific construct and sub-constructs. To accomplish this, opinion on the content was sought of management staffs and experts including the study supervisors. Additionally, the questions were drawn from empirical studies (Carrin, 2003) and tailored to fit the Kenyan situation.

\subsection{Data Analysis}

Descriptive statistics was used to compare the values numerically where a likert scale was used to rate the extent of agreement on the given constructs of government stewardship in CBHIs in a scale of 1 to 5 where 1 is the least extent whereas 5 is the maximum indicating the level of agreement. The results from the collected responses were analyzed based on means and their standard deviations to show the variability of the individual responses from the overall mean of the responses per each aspect of enrollment strategy. The strength of linear relationship between sub-constructs of the independent variable (mix of contributions) and the sub-constructs under the dependent variable - equity in health care (healthcare access, equity in contributions, quality of care and sustainability) was determined using Karl Pearson's coefficient of correlation. Structural equation modelling (SEM) partial least square (PLS) approach was used to develop the measurement and structural model for testing hypothesized relationships between the two variables and for bootstrapping.

\section{Findings and Discussion}

4.1 Households targeted and average enrolement in CBHIs

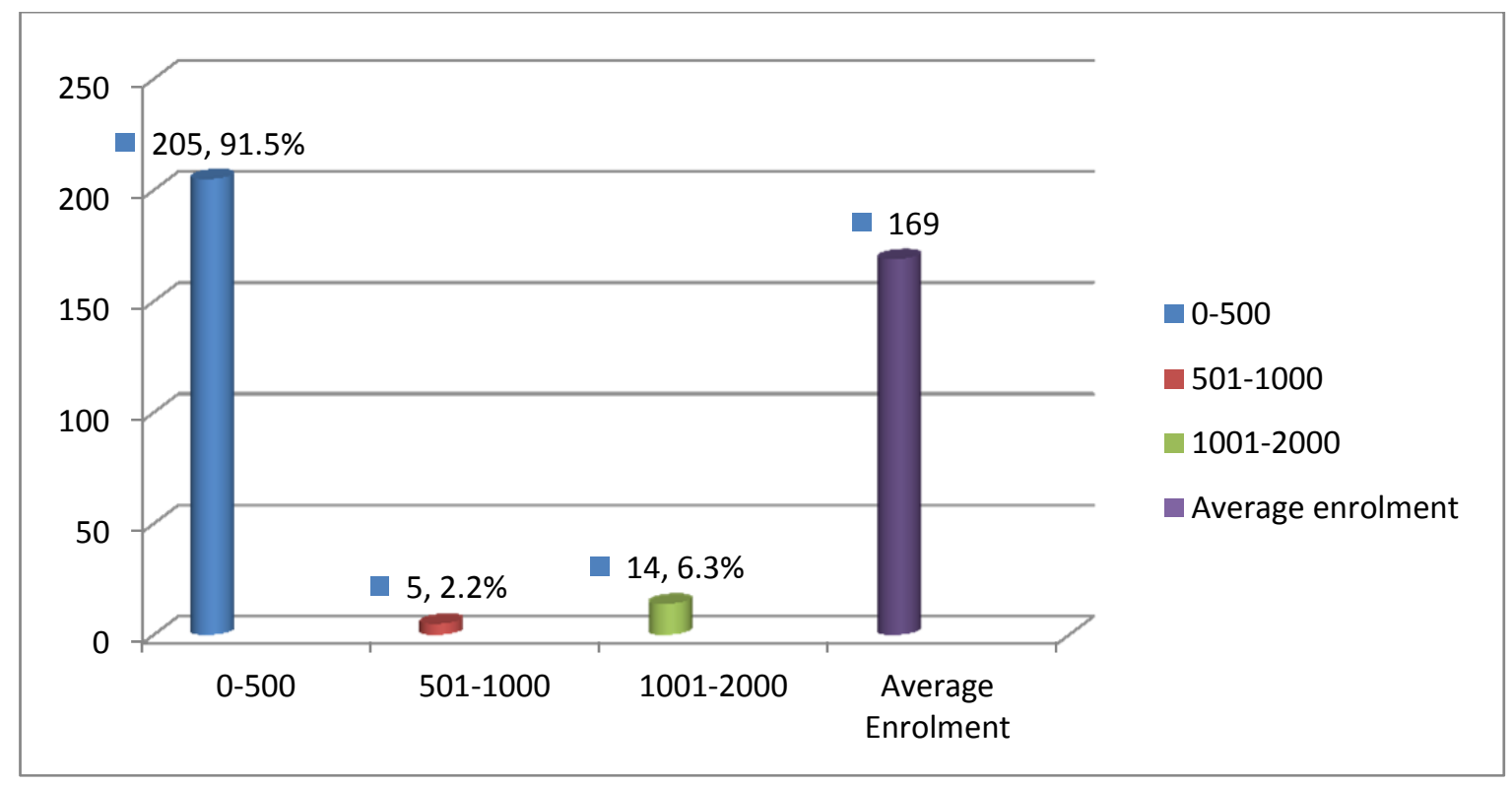

Figure 1. Households Covered by CBHIs and Average Enrolment 
With regard to the number of households covered by the CBHIs, majority (91.5\%) of these CBHIs covered up to 500 households, $6 \%$ covered between 1001-2000 households whereas $2 \%$ covered between 501-1000 households in their operations as shown in Figure 1.

\subsection{Average Mix of Contributions in CBHIs}

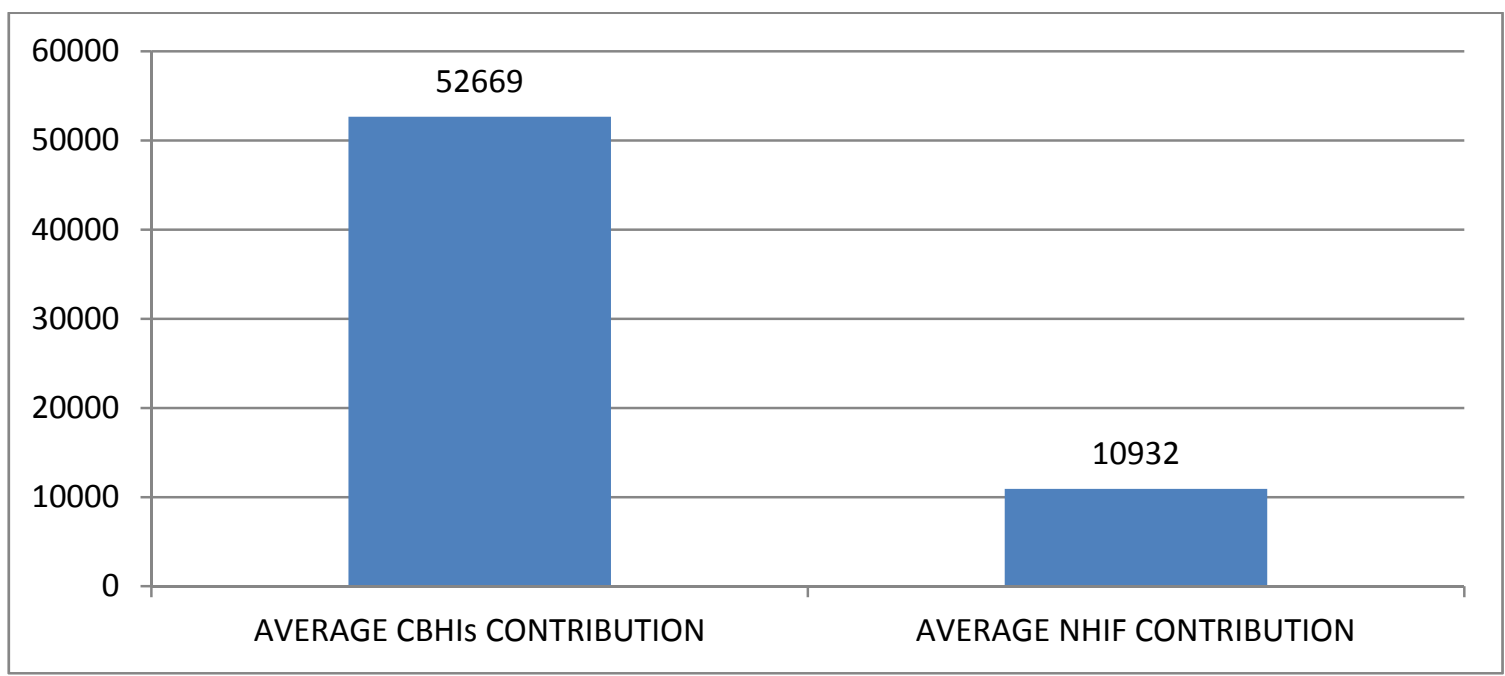

Figure 2. Average Mix of Contributions in CBHIs

Figure 2 shows that the mean NHIF contribution through CBHIs was 52,668.831 while the mean CBHIs contribution was 109,315.08.

4.3 Trends of Total Premiums Collected, Healthcare Cost Reimbursements, Administration Cost and Deficit/Surplus in CBHIs between 2010-2015

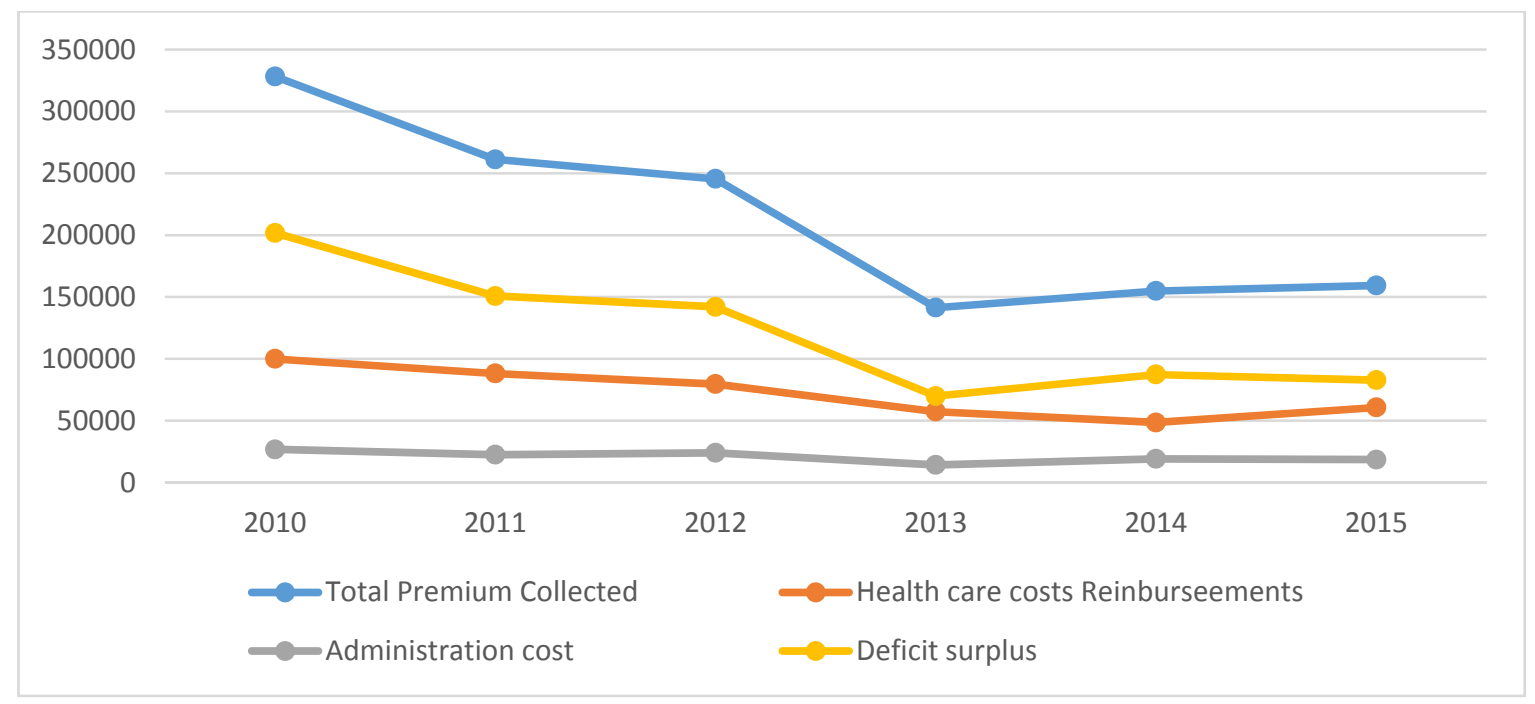

Figure 3. Trends of Total Premiums collected, healthcare cost reimbursements, administration cost and deficit/surplus in CBHIs between 2010-2015

Figure 3 on trends of total premiums collected, healthcare cost reimbursements, administration cost and deficit/surplus in CBHIs between year 2010-2015 shows a sharp decrease in total premiums collected and surplus 
between year 2010 and 2013 followed by a slight increase in the next two years. The healthcare cost decrease gradually between year 2010 and 2014 followed by a slight increase in year 2015. However, the administration cost remained constant throughout the entire period. The low premiums collected in 2015 compared to 2010 collection can be attributed to low renewal rates for the composite CBHIs and NHIF products following the increase of NHIF rates for the informal sector.

4.4 Mix of Contributions Scores

Table 1. Descriptive Analysis - Extent Effect of Mix of Contributions in CBHIs on Equity in Healthcare

\begin{tabular}{|c|c|c|c|c|c|c|c|}
\hline Mix of Contributions & $\begin{array}{l}\text { Strongly } \\
\text { Disagree } \\
(\%)\end{array}$ & $\begin{array}{l}\text { Disagree } \\
(\%)\end{array}$ & $\begin{array}{l}\text { Neutral } \\
(\%)\end{array}$ & $\begin{array}{l}\text { Agree } \\
(\%)\end{array}$ & $\begin{array}{l}\text { Strongly } \\
\text { Agree (\%) }\end{array}$ & Mean & $\begin{array}{l}\text { Std. } \\
\text { Dev }\end{array}$ \\
\hline $\begin{array}{l}\text { Members' contributions are } \\
\text { adequate in meeting the cost of } \\
\text { the set benefit package }\end{array}$ & 4 & 54 & 38 & 4 & 0 & 2.45 & .661 \\
\hline $\begin{array}{l}\text { NHIF covers costs of services not } \\
\text { covered by the CBHIs }\end{array}$ & 0 & 0 & 3 & 30 & 67 & 4.64 & .533 \\
\hline $\begin{array}{l}\text { The CBHIs receives financial } \\
\text { support from donor(s) }\end{array}$ & 0 & 36 & 58 & 5 & 0 & 2.69 & .592 \\
\hline $\begin{array}{l}\text { The poor and vulnerable } \\
\text { members of the CBHIs are } \\
\text { covered through government } \\
\text { subsidies }\end{array}$ & 0 & 38 & 56 & 5 & 0 & 2.67 & .597 \\
\hline
\end{tabular}

Table 1 discloses the study findings on the mix of contributions. As reported NHIF covers costs of services not covered by the CBHIs for the members (mean $=4.64$; std. dev. $=0.533$ ). However, some of the CBHIs receives financial support from donor(s) whereas others had no such connections and donor support (mean $=2.69$; std. dev. $=0.592$ ), members' contributions are not adequate in meeting the cost of the set benefit package (mean $=2.45$; std. dev. $=0.661$ ) and the poor and vulnerable members of the CBHIs are covered through government subsidies (mean $=2.69$; std. dev. $=0.597$ ).

\subsection{Mix of Contributions and Equity in Healthcare Sub-Constructs}

Table 2. Correlation between Mix of Contributions and Healthcare Access

\begin{tabular}{lll}
\hline & Healthcare Access & \\
\hline \multirow{3}{*}{ Mix of Contributions } & Pearson Correlation & -.035 \\
& Sig. (2-tailed) & .599 \\
& $\mathrm{~N}$ & 224 \\
\hline
\end{tabular}

Table 3. Correlation between Mix of Contributions and Equity in Contributions

\begin{tabular}{lll}
\hline & Equity in Contributions \\
\hline \multirow{3}{*}{ Mix of Contributions } & Pearson Correlation & $\cdot$ \\
& Sig. (2-tailed) & $\cdot$ \\
& $\mathrm{N}$ & 224 \\
\hline
\end{tabular}


Table 4. Correlation between Mix of Contributions and Quality of Care

\begin{tabular}{llc}
\hline & & Quality of Care \\
\hline \multirow{3}{*}{ Mix of Contributions } & Pearson Correlation & -.114 \\
& Sig. (2-tailed) & .088 \\
& $\mathrm{~N}$ & 224 \\
\hline
\end{tabular}

Table 5. Correlation between Mix of Contributions and Sustainability

\begin{tabular}{llc}
\hline & & Sustainability \\
\hline \multirow{3}{*}{ Mix of Contributions } & Pearson Correlation & -.127 \\
& Sig. (2-tailed) & .058 \\
& $\mathrm{~N}$ & 224 \\
\hline
\end{tabular}

Pearson correlation coefficient in table 2 to 5 show an insignificant relationships between the mix of contributions and three of the sub-constructs under equity in healthcare including healthcare access $(r=-.035, p>.05)$, quality of care $(r=-.114, p>.05)$ and sustainability $(r=-.127, p>.05)$. Mix of contributions and equity in contributions did not show any relationship. Risk pooling in CBHIs had a positive statistically and significant effect on equity in healthcare $(\beta=0.553$, $\mathrm{t}$-value $=10.841>1.96, \mathrm{p}<0.05)$.

\subsection{Mix of Contributions and Equity in Healthcare}

4.6.1 Cronbach's Alpha Coefficients, AVE and KMO values for Mix of Contributions

Cronbach's alpha coefficients were above the 0.7 threshold for all first order constructs, total item correlations of above 0.3 , AVE of above $65 \%$, KMO values greater than 0.5 and satisfactory principal component loadings of above 0.50 as reported in table 6 . The factors with low standardized regression weights were subsequently deleted. These findings imply that the items of measure were measuring what they were initially set out to measure, and therefore the data was maintained for further analysis.

Table 6. Cronbach's Alpha Coefficients, AVE and KMO values for Mix of Contributions

\begin{tabular}{llllllll}
\hline $\begin{array}{l}\text { First order } \\
\text { constructs }\end{array}$ & $\begin{array}{l}\text { Cronbach's } \\
\text { alpha }\end{array}$ & Item & $\begin{array}{l}\text { Item total } \\
\text { correlation }\end{array}$ & KMO & $\begin{array}{l}\text { PCA } \\
\text { component } \\
\text { loading }\end{array}$ & $\begin{array}{l}\text { variance } \\
\text { extracted }\end{array}$ & $\begin{array}{l}\text { Items } \\
\text { deleted }\end{array}$ \\
\hline $\begin{array}{l}\text { Mix of } \\
\text { Contribution }\end{array}$ & 0.714 & $\mathrm{MC} 2$ & 0.523 & 0.500 & 0.715 & 0.715 & MC1,MC3 \\
\hline
\end{tabular}

\subsubsection{Relationship between Mix of Contributions and Equity in Healthcare}

\section{Hypothesized effect of Mix of Contributions in CBHIs on equity in healthcare}




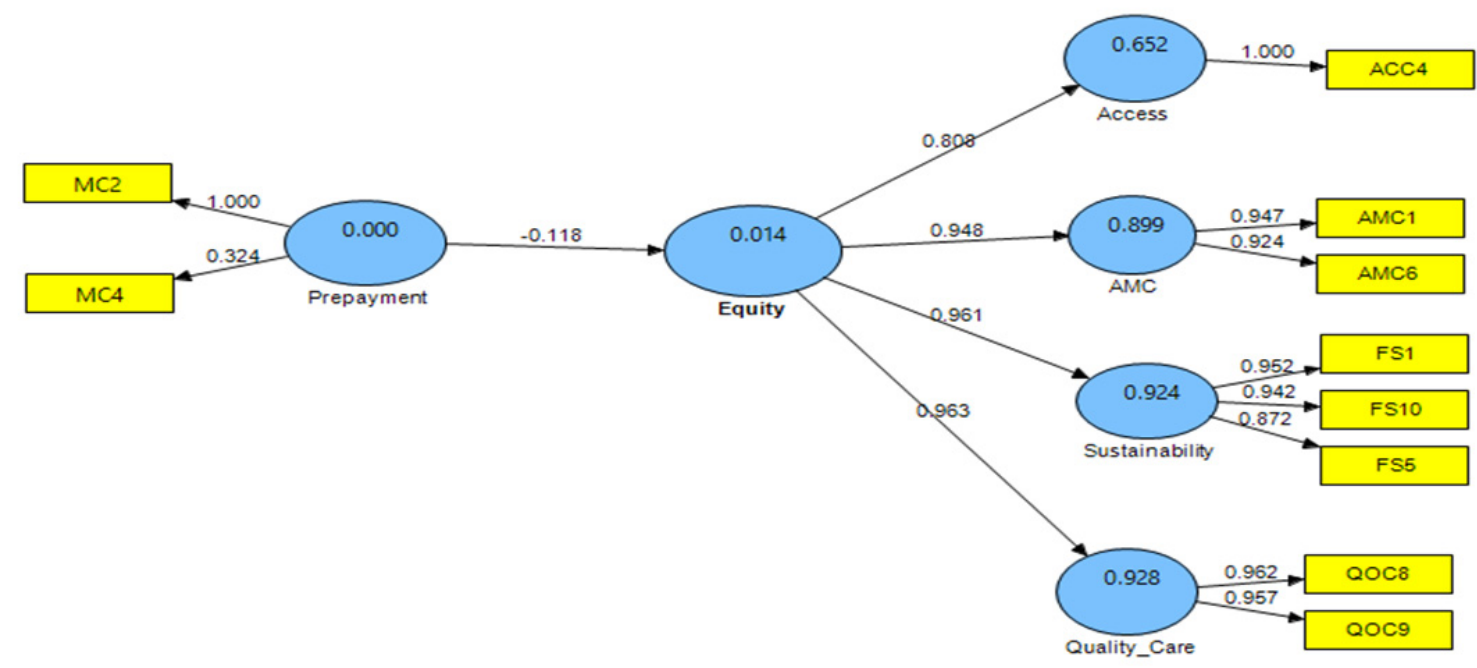

Figure 4. Path coefficients for effect of mix of contributions on equity in healthcare in CBHIs

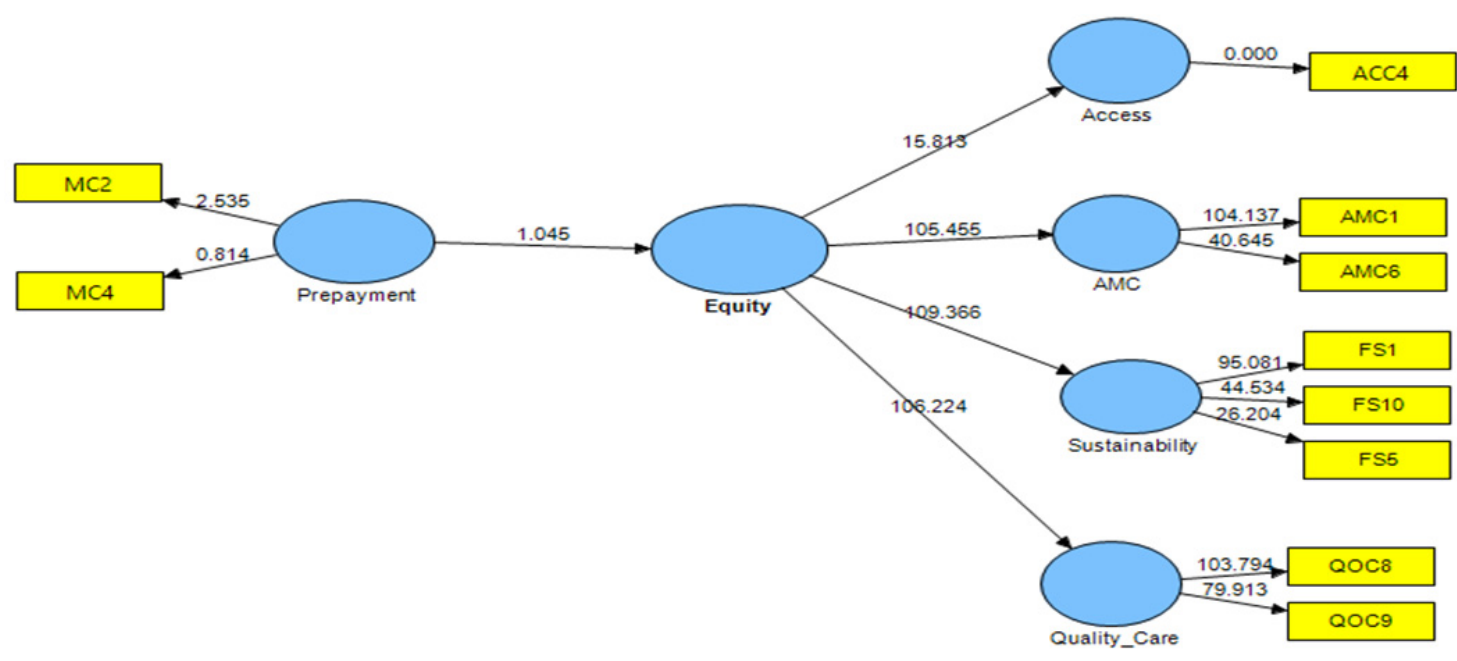

Figure 5. t-values for effect of mix of contributions on equity in healthcare in CBHIs

Table 7. Path Coefficients (Mean, STDEV, t-values)

\begin{tabular}{lllllc}
\hline & $\begin{array}{l}\text { Original } \\
\text { Sample (O) }\end{array}$ & $\begin{array}{l}\text { Sample Mean } \\
(\mathrm{M})\end{array}$ & $\begin{array}{l}\text { Standard } \\
\text { Deviation } \\
\text { (STDEV) }\end{array}$ & $\begin{array}{l}\text { T Statistics } \\
(\mid \mathbf{O} / \text { STDEV } \mid)\end{array}$ & P Values \\
\hline Mix of Contributions -> Equity & -0.117995 & -0.098878 & 0.112944 & 1.044718 & 0.29666 \\
\hline
\end{tabular}

Mix of contributions in CBHIs had a negative and insignificant effect on equity in healthcare at the 0.05 level of significance $(\beta=-0.118$, $\mathrm{t}$-value $=1.045<1.96, \mathrm{p}>0.05)$ as shown in Figures 4 and 5 and Table 7 .

The WHO report of 2010 postulates prepayments as the most efficient and equitable method of raising funds for healthcare. Hypothecated, general and payroll taxes, insurance or a combination of two have been hailed as the most progressive ways of funding healthcare for universal coverage (Doetinchem, 2010; Durairaj \& Evans, 2010). The study finding revealed that membership contributions are the only source prepayments in CBHIs. Members pre-pay through both CBHIs and NHIF. In addition, the current study found that majority of CBHIs (88.3\%) covered up to 500 households. This hampers their ability to mobilize adequate resources required for achieving equity in healthcare. This finding agree with Tabor (2005) \& Schieber et al. (2012) that found that CBHIs face a challenge of mobilizing sufficient resources attributable to their small size and the contributory capacity of the 
target population (Tabor, 2005; Schieber et al., 2012). Finding on the trends of total premiums collected, healthcare cost reimbursements, administration cost and deficit or surplus in CBHIs between 2010-2015 shows an up and down fluctuation of the total premiums collected, healthcare cost reimbursements and deficit or surplus while the administration cost remained constant throughout the entire period.

The study found that the poor and vulnerable are covered through government and or donor funding. The findings are however not channeled through CBHIs which means that the finding is at odds with the recommendations of WHO (2010) on creation of health equity funds that exempt the poorest and vulnerable group and subsidize the poor. Further, the finding also disagrees with recent practices from Rwanda and Ghana where health equity funds have ensured rapid inclusion of the poorest and vulnerable groups (Durairaj et al., 2010; WHO, 2010).

\section{Limitations of the Study}

The data used in the analysis was collected from CBHIs in Kenya. Although other forms of community financing schemes such payment of user fees for healthcare at the point and time of use exist in Kenya they were not the focus in this study.

\section{Conclusions}

The negative relationship between mix of contributions and equity in healthcare access in CBHIs in Kenya suggest lack of the right combination of contributions necessary for realization and sustenance of equity in healthcare through CBHIs particularly for the excluded segments of the population. The current mix of contributions in CBHIs is composed of CBHIs and NHIF premium contributions only. The composite CBHIs and NHIF products covers services that are not covered by the CBHIs cover. Although the study did not establish existence of any form of direct government and or donor subsidies through CBHIs, findings shows that poor and vulnerable members of CBHIs benefit from some form of subsidies from government or donor funding. This can be explained by the fact that government offers free healthcare at level 2 and 3 facilities that is funded by HSSF. Although it is fraught with shortcomings, the waiver system also caters for all or part of healthcare costs in level 4 and 5 facilities. Absence of contributions from government and or donors to subsidize or exempt the poor and vulnerable through CBHIs hampers extension of equity in healthcare to these groups. The study then concludes that current mix of contributions composed of only CBHIs and NHIF the members' contributions is not adequate enough to allow for reallocation of resources for subsidization or exemption of poor and vulnerable groups. The current mix does not offer an optimal mix of funds necessary for increased access to care and financial risk protection for precluded groups. The study recommends that there is need for a clear definition of CBHIs place within national health policies to guide their administrative and fiscal structures for increased access to care and financial risk protection in countries where CBHIs play a complementary role of extending health insurance to precluded segments of the population.

\section{Competing Interests Statement}

The authors declare that they has no competing or potential conflicts of interest.

\section{References}

Asante, A., Price, J., Hayen, A., Jan, S., \& Wiseman, V. (2016). Equity in Health Care Financing in Low- and Middle-Income Countries: A Systematic Review of Evidence from Studies Using Benefit and Financing Incidence Analyses. PLOS ONE, 10, 1371.

Carrin, G. (2003). Community based Health Insurance Schemes in Developing Countries: facts, problems and perspectives. Geneva: WHO.

Carrin, G., et al. (2007). Health financing reform in Kenya - assessing the social health insurance proposal. $S$ Afr Med J, 97, 130-135.

Chuma, J., \& Maina, T. (2012). Catastrophic health care spending and impoverishment in Kenya. BMC Health Services Research, 12, 413. https://doi.org/10.1186/1472-6963-12-413

Chuma, J., \& Okungu, V. (2011). Viewing Kenyan health system through an equity lens: Implications for Universal Health Coverage. International Journal for Equity in Health, 10, 22. https://doi.org/10.1186/1475-9276-10-22

Criel, B., \& Van Dormael, M. (1999). Mutual health organizations in Africa and social health insurance systems: Will European history repeat itself? Tropical Medicine and International Health, 4, 155-159. https://doi.org/10.1046/j.1365-3156.1999.43385.x

Fernandes, A et al. (2009). Health financing systems review of Rwanda-options for universal coverage. World 
Health Organization and Ministry of Health, Republic of Rwanda HEALTH.

KNBS. (2016). Economic Survey 2016.

Kruk, M.E., Goldmann, E., \& Galea, S. (2009). Borrowing and Selling to Pay for Health Care in Low- and Middle-Income Countries. Health Affairs, 28, 1056-66. https://doi.org/10.1377/hlthaff.28.4.1056

Ministry of Health. (2015). Kenya National Health Accounts 2012/13. Nairobi: Ministry of Health.

MoH. (2014). 2013 Kenya Household Health Expenditure and Utilisation Survey. Nairobi: MoH.

Poletti, T., Balabanova, D., Ghazaryan, O., Kamal-Yanni, M., Kocharyan, H., Arakelyan, K., \& Hakobyan, M. (2007). Options for scaling up community-based health insurance for rural communities in Armenia. Health Systems Development Programme. London School of Hygiene and Tropical Medicine: London.

Schieber, G., Cashin, C., Saleh, K., \& Lavado, R. (2012). Health Financing in Ghana. Washington DC: The World Bank. https://doi.org/10.1596/978-0-8213-9566-0

Starfield, B. (2011). The hidden inequity in health care. International Journal for Equity in Health, 10, 15. https://doi.org/10.1186/1475-9276-10-15

Tabor, S. R. (2005). Community-based health insurance and social protection policy. Washington DC: World Bank.

WHO. (2010). Health Systems Financing - The path to universal coverage. Geneva: WHO.

WHO. (2015a). Do health expenditures meet health needs? Geneva: WHO HEALTH.

WHO. (2015b). External AID for health remains insufficient in low income countries. WHO/HA Policy Highlight No.3. Geneva : WHO.

WHO. (2016). World Health Statistics: Monitoring health for the SDGs. Geneva : WHO.

\section{Copyrights}

Copyright for this article is retained by the author(s), with first publication rights granted to the journal.

This is an open-access article distributed under the terms and conditions of the Creative Commons Attribution license (http://creativecommons.org/licenses/by/4.0/). 